\title{
In vivo Confocal Microscopy Report after Lasik with Sequential Accelerated Corneal Collagen Cross-Linking Treatment
}

\author{
Cosimo Mazzotta ${ }^{a} \quad$ Angelo Balestrazzi ${ }^{a} \quad$ Claudio Traversi ${ }^{a}$ \\ Stefano Caragiulia ${ }^{a}$ Aldo Caporossi ${ }^{b}$ \\ ${ }^{a}$ Department of Ophthalmology, Siena University Hospital, Siena, and ${ }^{b}$ Department of \\ Ophthalmology, Rome Catholic University, Rome, Italy
}

\section{Key Words}

Laser in situ keratomileusis · Accelerated corneal collagen cross-linking · Confocal microscopy

\begin{abstract}
We report the first pilot qualitative confocal microscopic analysis of a laser in situ keratomileusis (Lasik) treatment combined with sequential high-fluence accelerated corneal collagen cross-linking, denominated Lasik XTra, by means of HRT II laser scanning in vivo confocal microscopy after a 6-month follow-up. After obtaining approval from the Siena University Hospital Institutional Review Board, a 33-year-old female patient underwent a Lasik XTra procedure in her left eye. Confocal analysis demonstrated induced slight corneal microstructural changes by the interaction between UV-A, riboflavin and corneal stromal collagen, beyond the interface to a depth of $160 \mu \mathrm{m}$, without adverse events at the interface and endothelial levels. This application may be considered a prophylactic biomechanical treatment, stiffening the intermediate corneal stroma to prevent corneal ectasia and stabilizing the clinical results of refractive surgery. According to our preliminary experiences, this combined approach may be useful in higher-risk Lasik patients for hyperopic treatments, high myopia and lower corneal thicknesses.

(C) 2014 S. Karger AG, Basel
\end{abstract}

\section{Introduction}

Corneal collagen cross-linking treatment demonstrated a long-term efficacy in the treatment of primary and secondary (post-Lasik and post-RK) corneal ectasias [1, 2]. 
Mazzotta et al.: In vivo Confocal Microscopy Report after Lasik with Sequential Accelerated Corneal Collagen Cross-Linking Treatment

Confocal microscopy studies in standard and accelerated corneal collagen cross-linking showed that the penetration of the treatment, estimated on keratocyte apoptosis, is inversely proportional to UV-A power (the higher UV-A power produces lower penetration) and directly proportional to exposure time (the longer UV-A exposure time produces higher penetration) $[3,4]$.

Recently, accelerated corneal collagen cross-linking with high fluence was performed concurrently with laser in situ keratomileusis (Lasik) in a small group of patients in order to prevent corneal ectasia after Lasik treatment, reporting good clinical results [5]. It was also applied to prevent regression in post-Lasik hyperopic and high myopia treatments. The results in these pilot case series suggest that an evaluation of a larger study cohort is warranted to establish the utility of this treatment $[6,7]$.

Kanellopoulos and Asimellis [8] recently published 43 consecutive sequential Lasik plus accelerated corneal collagen cross-linking procedures. All eyes at the completion of Lasik had cross-linking through the repositioned flap, with higher fluence $\left(10 \mathrm{~mW} / \mathrm{cm}^{2} \mathrm{UV}\right.$-A light of an average of $370 \mu \mathrm{m}$ wavelength) applied for 3 min following an earlier single instillation of $0.1 \%$ riboflavin within the flap interface. The average follow-up duration was 3.5 (range 1.0-4.5) years. The authors concluded that prophylactic collagen cross-linking for high-risk Lasik cases appeared to be a safe and effective adjunctive treatment for refractive regression and potential ectasia.

According to preliminary literature [9], this combined application may be viewed as prophylactic customization of the biomechanical behavior of corneal collagen. More recently the same author reported good results by using Avedro's KXL I device (Waltham, Mass., USA) at the higher UV-A power of $30 \mathrm{~mW} / \mathrm{cm}^{2}$, for a total of $80 \mathrm{~s}$, in order to achieve a stromal collagen cross-linking [9].

Here, we report a pilot qualitative confocal microscopic study on a patient undergoing Lasik combined with sequential accelerated corneal collagen cross-linking (Lasik XTra) by means of HRT II laser scanning in vivo confocal microscopy after a 6-month follow-up.

\section{Case Report}

After approval by the Siena University Hospital Review Board and a specific-informed consent signature, a 33-year-old female patient underwent a Lasik XTra procedure (Lasik combined with sequential high-fluence cross-linking) in her left eye. Treatment parameters of the left partially amblyopic eye were: $-5 \mathrm{dpt}$ of myopia with a corrected distance visual acuity of 20/40. Her fellow eye (right) had 20/20 uncorrected distance visual acuity. Preoperative optical pachymetry of the treated eye was $530 \mu \mathrm{m}$ in the thinnest point. Endothelial cell count was 2,770 cells $/ \mathrm{mm}^{2}$. The preoperative ideal pupil diameter was 6 $\mathrm{mm}$ (C.S.O. Eye Top Pupillometer, Florence, Italy). The preoperative corneal topography was within normal limits.

The Lasik procedure (fig. 1) was performed by the IntraLase ${ }^{\mathrm{TM}}$ FS Laser (Abbott Medical Optics Inc., AMO Santa Ana, Calif., USA). A 95- $\mu$ m-thick flap was programmed with superior nasal hinge; after Lasik cut and flap lifting, the excimer laser treatment was performed by a Technolas 217z, 100-Hz Excimer Laser (Bausch and Lomb), setting the following parameters: $-5 \mathrm{dpt}$ of myopia with a 6.4-mm optical zone and tissue-saving algorithm (Zyoptix). After excimer laser treatment, the corneal stroma was soaked with a riboflavin $0.25 \%$ saline solution for $90 \mathrm{~s}$ (VibeX Xtra, Avedro, Waltham, Mass., USA), then the surface was rinsed with a balanced salt solution, the flap repositioned and UV-A irradiation applied over the 
Mazzotta et al.: In vivo Confocal Microscopy Report after Lasik with Sequential Accelerated Corneal Collagen Cross-Linking Treatment

epithelial surface for $90 \mathrm{~s}$ of continuous light illumination at $30 \mathrm{~mW} / \mathrm{cm}^{2}$ (energy dose of 2.7 $\mathrm{J} / \mathrm{cm}^{2}$ ) according to Avedro's Lasik Xtra protocol.

After UV-A radiation the cornea was medicated with antibiotic (ciprofloxacin) and nonsteroidal anti-inflammatory eyedrops (diclofenac). In vivo HRT II scanning laser confocal analysis was performed 1 week, 3 and 6 months after treatment. The postoperative in vivo micromorphological analysis (fig. 2) revealed the following: the epithelium (fig. 2a) showed slight alterations due to UV-A radiation, demonstrating areas of missing cells in the first 15 days after treatment. At 1, 3 and 6 months, the epithelial healing and cell stratification was within the normal limits. Nerves showed a rarefaction of subbasal and subepithelial fibers after UV-A radiation. Even if subjected to slight damage, the subepithelial fibers did not disappear after Lasik Xtra as shown in a confocal scan (fig. 2b).

Stromal healing demonstrated a slight microlacunar edema that was present in the first month after treatment into the flap's stroma up to $100 \mu \mathrm{m}$ of depth; spared keratocyte nuclei were detected with increased reflectivity (cell activation) into the flap upon the interface, as shown in confocal scans (fig. 2c, d).

The interface was hypocellular and well-distinguished, containing numerous hyperreflective microspots or bright particles as revealed by confocal images (fig. 2e, f).

The stroma beyond the interface demonstrated relevant interactions between UV-A, riboflavin and corneal collagen (fig. $2 \mathrm{~g}$ ) with evident keratocyte apoptosis, documented by rarefaction of keratocyte nuclei and diffuse edema, until a depth of $60 \mu \mathrm{m}$ over the interface, where the apoptotic phenomena ended, resembling the normal appearance of the stroma shown as well in fig. $2 \mathrm{~h}$ and i. The intermediate stroma beyond $160 \mu \mathrm{m}$ and the deep stroma were unreached by the combined photoablative, photodisruptive and photooxidative damage, as documented by the presence of normal keratocyte nuclei (fig. $2 \mathrm{j}, \mathrm{l}$ ).

Corneal endothelium examined in the first 15 days after treatment showed an area of missing cells similar to guttae (fig. 2l) suspecting a potential hot-spot area induced by highintensity UV-A power or related to poor corneal thickness. However, this aspect disappeared during the follow-up and might also be interpreted as possible early artifact due to stromal edema. Indeed no changes in endothelial cell count $\left(2,739\right.$ cells $/ \mathrm{mm}^{2}$ at the 6 th month) were recorded during the follow-up and the endothelium assumed a slight pleomorphic appearance as shown in fig. 3 .

\section{Discussion}

Confocal microscopy performed after Lasik Xtra enables us to assess the microstructural changes induced by the treatment from epithelium to endothelium.

Epithelial basal cells showed an immediate slight damage related to a direct cytotoxic effect of UV-A irradiation; however, the epithelium appeared normal in the first month after treatment. The natural shielding effect provided by the epithelium itself [9-12], not soaked with riboflavin, absorbs about $25 \%$ of UV-A rays.

After Lasik Xtra, the nerve fibers of the subepithelial plexus did not disappear. Only a slight nerve rarefaction was recorded, reasonably due to femtosecond laser flap sculpture (applanation and photodisruption) and less to UV-A radiation. Stromal nerves disappeared reasonably due to flap femtosecond laser sculpture and excimer laser photoablation.

Keratocyte apoptosis into the flap was poor and associated with a slight and diffuse stromal edema reaching the wound interface. The interface plane was found at about 100 $\mu \mathrm{m}$, appearing markedly hypocellular with numerous hyperreflective bright particles; soaking with the riboflavin solution may require a longer interface washing to avoid the 
permanence of detritus, or the surgeon should lift the flap rewashing the stromal plane at the end of the procedure. Spared keratocyte activation into the flap upon the interface may be related to UV-A toxicity while beyond the interface we did not observe any cell activation. Keratocyte apoptosis, indeed, was maximum beyond the wound interface reaching a depth of $150-160 \mu \mathrm{m}$. The alterations in corneal stroma underlying the interface can be caused by the combined effect of photodisruption (femtosecond laser), photoablation (excimer laser), and photooxidative damage (UV-A cross-linking). Confocal microscopy analysis after standard femto-Lasik treatments for myopia revealed that keratocytes tend to disappear around the wound interface but, at the same time, other keratocytes show activation [13]. Conversely, in this confocal analysis, keratocyte apoptosis and corneal edema were present beyond the interface, without fibrosis and activated keratocyte nuclei. The presence of a more evident corneal edema, without keratocyte activation, may reasonably depend on adjunctive interactions between riboflavin molecules, UV-A photons and stromal collagen that mainly occur from the interface plane (not into the flap) until a depth of 50-60 $\mu \mathrm{m}$ of corneal stroma beyond the interface in femto-Lasik with adjunctive high-fluence UV-A crosslinking. Indeed, over $160 \mu \mathrm{m}$ of stromal depth, measured from the epithelial surface, there are no appreciable changes.

During the follow-up, corneal edema disappeared gradually and keratocyte repopulation was complete at the 6th month. No changes in the density of the extracellular matrix, nor evidence of stromal nerve regeneration were recorded at the 6th month.

At present, we do not exactly know the utility of a widely used prophylactic combination between Lasik and sequential accelerated cross-linking, even if this study demonstrated no adverse events on the corneal interface, stroma and endothelium. According to preliminary experiences, the Lasik Xtra may determine a reasonable biomechanical stiffening of the intermediate stroma beyond the interface and a strongest adherence between the flap and the corneal stroma (glue effect) [14].

A large cohort of patients is needed to determine the clinical significance and the utility of this combined refractive surgical therapy. Our patient was well 6 months after treatment, reporting an uncorrected distance visual acuity of 20/40. In our opinion this combined approach may be qualitative in the field of refractive surgery and reasonably effective in treating higher-risk Lasik patients such as hyperopic, high myopic patients and those with lower corneal thickness (under $500 \mu \mathrm{m}$ ).

\section{References}

1 Hafezi F, Kanellopoulos J, Wiltfang R, Seiler T: Corneal collagen crosslinking with riboflavin and ultraviolet A to treat induced keratectasia after laser in situ keratomileusis. J Cataract Refract Surg 2007;33:2035-2040.

-2 Mazzotta C, Baiocchi S, Denaro R, Tosi GM, Caporossi T: Corneal collagen cross-linking to stop corneal ectasia exacerbated by radial keratotomy. Cornea 2011;30:225-228.

-3 Mazzotta C, Paradiso AL, Baiocchi S, Caragiuli S, Caporossi A: Qualitative investigation of corneal changes after accelerated corneal collagen cross-linking (A-CXL) by in vivo confocal microscopy and corneal OCT. J Clin Exp Ophthalmol 2013;313:4-6.

4 Mazzotta C, Traversi C, Baiocchi S, Caporossi O, Bovone C, Sparano MC, Balestrazzi A, Caporossi A: Corneal healing after riboflavin ultraviolet-A collagen cross-linking determined by confocal laser scanning microscopy in vivo: early and late modifications. Am J Ophthalmol 2008;146:527-533.

-5 Celik HU, Alagöz N, Yildirim Y, Agca A, Marshall J, Demirok A, Yilmaz OF: Accelerated corneal crosslinking concurrent with laser in situ keratomileusis. J Cataract Refract Surg 2012;38:1424-1431.

-6 Kanellopoulos AJ, Kahn J: Topography-guided hyperopic LASIK with and without high irradiance collagen cross-linking: initial comparative clinical findings in a contralateral eye study of 34 consecutive patients. J Refract Surg 2012;28(suppl):S837-S840. 


\begin{tabular}{l|l}
\hline Case Rep Ophthalmol 2014;5:125-131 \\
\hline DOI: 10.1159/000362327 & $\begin{array}{l}\text { @ 2014 S. Karger AG, Basel } \\
\text { www.karger.com/cop }\end{array}$ \\
\hline
\end{tabular}

Mazzotta et al.: In vivo Confocal Microscopy Report after Lasik with Sequential Accelerated Corneal Collagen Cross-Linking Treatment

7 Kanellopoulos AJ: Long-term safety and efficacy follow-up of prophylactic higher fluence collagen crosslinking in high myopic laser-assisted in situ keratomileusis. Clin Ophthalmol 2012;6:1125-1130.

-8 Kanellopoulos AJ, Asimellis G: Comparison of Placido disc and Scheimpflug image-derived topographyguided excimer laser surface normalization combined with higher fluence CXL: the Athens Protocol, in progressive keratoconus. Clin Ophthalmol 2013;7:1385-1396.

\$9 Kolozsvári L, Nógrádi A, Hopp B, Bor Z: UV absorbance of the human cornea in the 240- to 400-nm range. Invest Ophthalmol Vis Sci 2002;43:2165-2168.

10 Cejková J, Stípek S, Crkovská J, Ardan T, Pláteník J, Cejka C, Midelfart A: UV rays, the prooxidant/antioxidant imbalance in the cornea and oxidative eye damage. Physiol Res 2004;53:1-10.

$\checkmark 11$ Podskochy A: Protective role of corneal epithelium against ultraviolet radiation damage. Acta Ophthalmol Scand 2004;82:714-717.

12 Ringvold A: Corneal epithelium and UV-protection of the eye. Acta Ophthalmol Scand 1998;76:149-153.

-13 Sonigo B, Iordanidou V, Chong-Sit D, Auclin F, Ancel JM, Labbé A, Baudouin C: In vivo corneal confocal microscopy comparison of intralase femtosecond laser and mechanical microkeratome for laser in situ keratomileusis. Invest Ophthalmol Vis Sci 2006;47:2803-2811.

14 Wollensak G, Spörl E, Mazzotta C, Kalinski T, Sel S: Interlamellar cohesion after corneal crosslinking using riboflavin and ultraviolet A light. Br J Ophthalmol 2011;95:876-880.
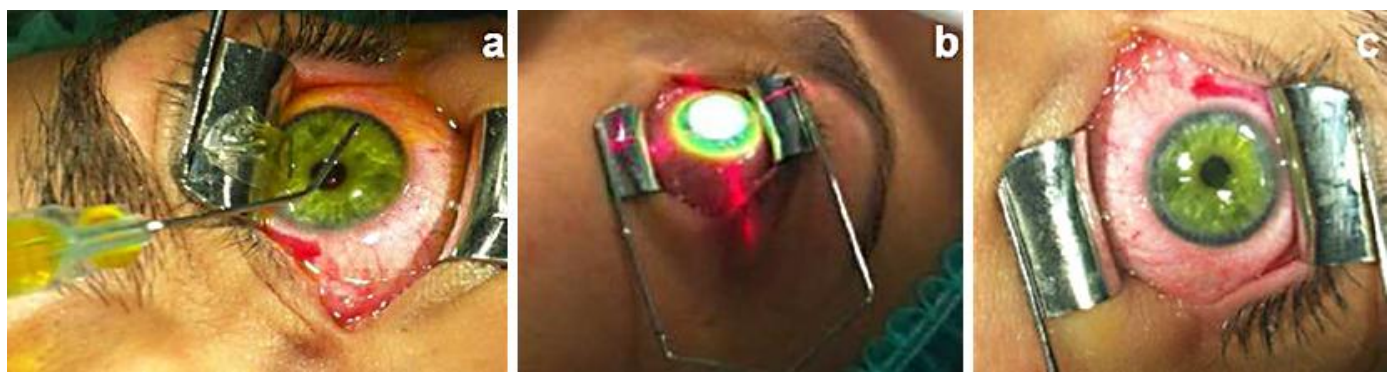

Fig. 1. a Lasik Xtra: after flap lifting and excimer laser treatment, the corneal stroma is soaked by riboflavin $0.25 \%$ saline solution (VibeX Xtra) for $90 \mathrm{~s}$. b After $90 \mathrm{~s}$ of riboflavin soaking, the corneal surface is washed with balanced salt solution and the flap repositioned. Then, accelerated high-fluence corneal collagen cross-linking was performed at $30 \mathrm{~mW} / \mathrm{cm}^{2}$ for $90 \mathrm{~s}$ of UV-A exposure. $\mathrm{c}$ The final aspect of the cornea at the end of the treatment is shown. 


\begin{tabular}{l|l}
\hline Case Rep Ophthalmol 2014;5:125-131 \\
\hline DOI: 10.1159/000362327 & $\begin{array}{l}\text { C 2014 S. Karger AG, Basel } \\
\text { www.karger.com/cop }\end{array}$ \\
\hline
\end{tabular}

Mazzotta et al.: In vivo Confocal Microscopy Report after Lasik with Sequential Accelerated Corneal Collagen Cross-Linking Treatment

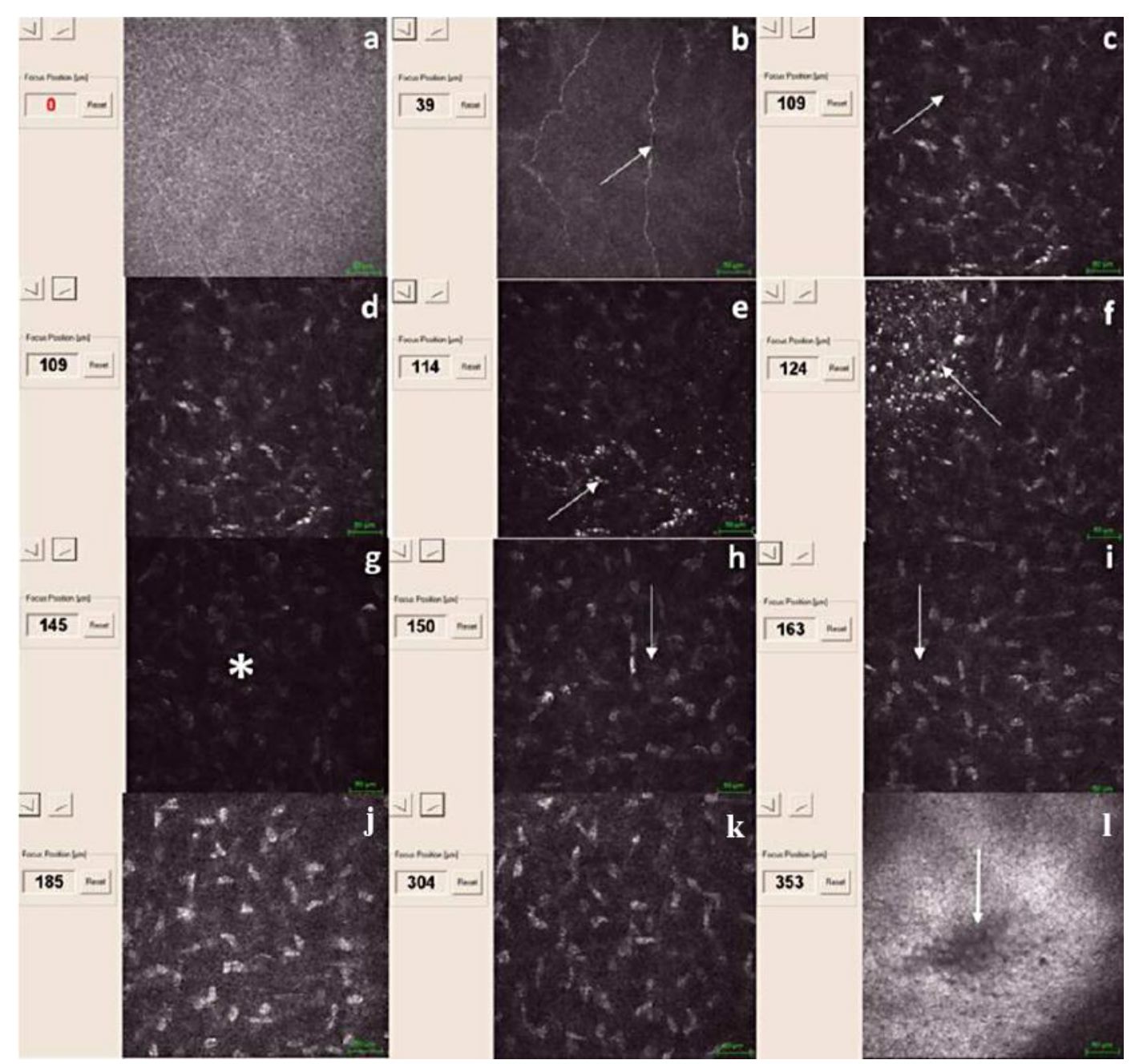

Fig. 2. Confocal microscopy overview in the first week after Lasik Xtra. a Undamaged basal epithelium. b Subepithelial plexus fibers did not disappear after treatment (arrow). c, d Slight keratocyte apoptosis associated with edema into the corneal flap before Lasik interface (arrow). e, f Lasik interface with bright hyperreflective particles (arrows). $\mathrm{g}$ Keratocyte apoptosis and increased edema beyond the interface until $150 \mu \mathrm{m}$ showing the area of maximum photooxidative impact, i.e. maximum riboflavin UV-A-collagen interaction (asterisk). $\mathbf{h}$, $\mathbf{i}$ Vertical transition area delimiting the end of photooxidative damage and apoptosis at $160 \mu \mathrm{m}$, i.e. riboflavin UV-A interaction (white arrows). $\mathbf{j}$ Intermediate stroma unreached by photooxidative damage, i.e. riboflavin UV-A interaction. $\mathbf{k}$ Deep stroma unreached by photooxidative damage, i.e. riboflavin UV-A interaction. I Corneal endothelium showing a circular area of pseudo-guttae (arrow). 
Case Reports in

Ophthalmology
Case Rep Ophthalmol 2014;5:125-131

DOI: $10.1159 / 000362327$ Mazzotta et al.: In vivo Confocal Microscopy Report after Lasik with Sequential
Accelerated Corneal Collagen Cross-Linking Treatment
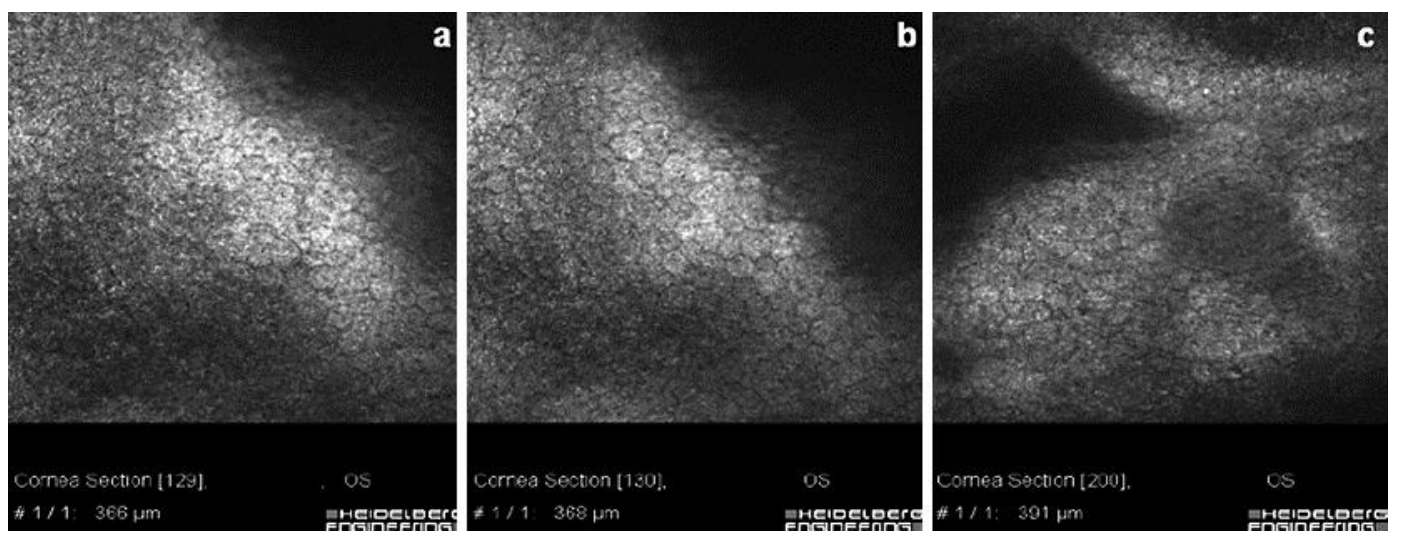

Fig. 3. Corneal endothelium at 1 (a), 3 (b), 6 (c) months after Lasik Xtra showing cell pleomorphism. No significant endothelial cell loss was established after treatment. 